\title{
The Three Rs of Academic Achievement: Reading, 'Riting, and Racism
}

\author{
Colette van Laar \\ Jim Sidanius \\ Joshua L. Rabinowitz \\ Stacey Sinclair \\ University of California, Los Angeles
}

Using vocational choice and social dominance theories as theoretical frameworks, the authors examined the effects of ideology/ role congruency on differential institutional rewards. The authors reasoned that congruents (i.e., individuals high in antiegalitarianism in hierarchy-enhancing [HE] social roles and low in antiegalitarianism in hierarchy-attenuating [HA] roles) would receive higher institutional rewards than would incongruents (i.e., individuals high in antiegalitarianism in $H A$ social roles and low in antiegalitarianism in HE roles). Furthermore, it was predicted that one's continued exposure to the university environment would increase the probability of being a congruent. The authors used a large sample of university students, with grade point average as the operationalization of institutional reward. Role was defined as the students' major, and antiegalitarianism was defined by a classical racism scale. As expected, (a) everything else being equal, congruents received higher grades than did incongruents, and (b) the probability of being a congruent increased with university experience.

he assumption that the congruence between workers' personalities and job types is associated with greater job satisfaction and occupational success has been a major theme within vocational psychology for some time (see, e.g., Gottfredson \& Holland, 1990; Henry, 1989; Holland, 1959, 1966, 1985; Mount \& Muchinsky, 1978; Posthuma \& Navran, 1970; cf. Tranberg, Slane, \& Ekeberg, 1993). Vocational psychologists have shown that not only is there a strong correspondence between an individual's abilities and interests and the environment in which he or she works but also that individuals tend to be more satisfied when there is such a correspondence (e.g., Mount \& Muchinsky, 1978; see Holland, 1996, for a review).

Although much of the work on congruence between an individual and his or her work environment focuses on the labor force, similar effects are observed at the college level. Such studies have found that college students are more satisfied when their interests match those of their major field (e.g., Nafziger, Holland, \& Gottfredson, 1975; also see Helms \& Williams, 1973). Other studies in education have found that experience within a field tends to increase the congruence between student and environment. For example, nationwide summer programs developed to encourage high school students to enter engineering resulted in students with high potential for engineering (as measured by grades, interests, and preparation), increasing their intentions to enter the engineering field, whereas those with little potential decreased their intentions to enter the field (Richards, Williams, \& Holland, 1978).

Although researchers in vocational psychology have emphasized the importance of the fit or congruence between the individual's general interests, aptitudes, and work environment, they have paid little or no attention to the fit between one's sociopolitical beliefs and the sociopolitical environment in which one is to work. Not surprisingly, however, specialists in the nature and function of political ideology have paid substantially more attention to the fit between the individual's ideology and the environment within which the individual works and lives. For example, Rokeach (1960) argued that not only do people with different personality types have different belief systems but also that different environments lead to the development of different belief systems. A synthe-

Authors' Note: We wish to thank David O. Sears for very helpful suggestions during the early phase of this work. Correspondence should be addressed to Colette van Laar, UCLA Department of Psychology, 405 Hilgard Avenue, Los Angeles, CA 90095-1563, e-mail: cvlaar@ucla.edu.

$P S P B$, Vol. 25 No. 2, February 1999 139-151

(C) 1999 by the Society for Personality and Social Psychology, Inc. 
sis of the literature on belief systems with that from vocational psychology would suggest that the congruence between one's sociopolitical beliefs and the dominant sociopolitical beliefs within the environment in which one works should also be important for one's success and overall job satisfaction.

Social dominance theorists have made recent efforts to explore the congruence between the individual's basic sociopolitical values and the social roles in which the individual functions. Social dominance theory asserts that societies tend to be organized as group-based social hierarchies with one or a small number of socially constructed groups at the top of this hierarchy and one or a number of other socially constructed groups at the very bottom of this hierarchy. Because the nature of this group-based structure is essentially arbitrary, these hierarchies can be based on ethnicity, race, clan, economic class, or any one of a number of other arbitrary and socially constructed group distinctions. Social dominance theorists maintain that such hierarchies are accompanied by two types of belief systems: hierarchyattenuating (HA) belief systems and hierarchy-enhancing (HE) belief systems (Pratto, Sidanius, Stallworth, \& Malle, 1994; Sidanius, 1993; Sidanius, Levin, \& Pratto, 1996; Sidanius, Pratto, Sinclair, \& van Laar, 1996). HE belief systems are defined as those that provide moral or intellectual justification for the establishment or maintenance of hierarchical and antiegalitarian relations among social groups. Examples of HE belief systems would be ideologies such as classism, sexism, aggressive nationalism, and racism. HA belief systems, on the other hand, are defined as those that act in the defense of relatively weak and subordinate social groups and that facilitate a more egalitarian allocation of positive social value across social groups. Examples of HA belief systems would be ideologies such as the universal rights of man, socialism, and racial egalitarianism (for a more detailed discussion of HE and HA belief systems, see Sidanius, Levin, et al., 1996).

Not only does social dominance theory (SD theory) suggest that belief systems can be classified as HE or HA, but SD theory suggests that social roles and institutions can be classified in this fashion as well. HE social institutions and social roles are those that tend to facilitate the disproportionate allocation of positive social value (e.g., high income, prestigious jobs, quality education, good housing, and good health) to members of dominant social groups and to allocate negative social value (e.g., prison sentences, torture, capital punishment, poor jobs, inferior education, poor housing, and poor health) to members of subordinate social groups. Examples of HE social roles and institutions are (a) criminal prosecutors, (b) the penal system, (c) police and internal security forces (e.g., FBI, KGB, Stassi, Shin Bet, Tonton Ma- coutes), and (d) corporate firms and their executives. SD theory suggests that the more powerful these HE institutions are relative to HA institutions (see below), the greater the inequality between dominant and subordinate social groups will be.

HA social roles and institutions have in common their tendency to aid the weak against the strong and help create greater levels of equality between dominant and subordinate social groups. Examples of HA social roles and institutions are (a) civil rights and human rights organizations, (b) the public defender's office, (c) labor organizers, and (d) social welfare organizations. SD theory further suggests that the effects of HE institutions and social roles tend to be blunted or moderated by the activities of HA institutions and social roles. The net result of these counterbalancing forces is relative stability in the level of the group-based system of social hierarchy (see Pratto et al., 1994; Sidanius, 1993; Sidanius \& Pratto, 1993; Sidanius, Pratto, \& Bobo, 1996).

Most pertinent for the discussion before us, SD theorists have argued that for $\mathrm{HE}$ and HA organizations to function most effectively, they should be staffed with personnel who have personalities and ideological predispositions that are congruent with the social roles they have to perform (see, e.g., Sidanius, Liu, Pratto, \& Shaw, 1994). For example, within SD theory, besides serving the widely accepted roles as the preservers of law and order, the police and internal security forces are also regarded as serving powerful HE social roles. These forces not only protect life and property but also function to preserve, protect, and help reproduce the hierarchical nature of the group-based social relations (see also Chevigny, 1995). Because of these additional, hierarchy-preserving social functions, SD theory expects that important HE institutions such as the police and internal security forces should tend to be staffed by personnel with relatively high levels of group-based, antiegalitarian values (e.g., racism, classism, SD orientation). Conversely, because SD theory regards HA organizations (e.g., social welfare and human rights groups) as agents of group-based social leveling, SD theorists would also expect incumbents of HA roles to be staffed by persons with relatively low levels of group-based, antiegalitarian values.

SD theorists have conducted a series of recent studies examining the interface between group-based antiegalitarianism and various forms of career choice. These studies have been most supportive of the expectations outlined above. For example, Sidanius, Liu, et al. (1994) found that members of the Los Angeles Police Department (i.e., HEs) had significantly higher levels of racism and social dominance orientation (SDO) ${ }^{1}$ than members of the general public, whereas members of the Los Angeles County Public Defenders Office (i.e., HAs) had 
significantly lower racism and social dominance scores than members of the general public even after controlling for a number of demographic factors (e.g., gender, age, education, social class). Similarly, using a sample of University of California, Los Angeles (UCLA) students, Sidanius, Pratto, Sinclair, et al. (1996) found a systematic series of correlations between the perceived attractiveness of HE and HA careers and SDO. The higher the students' level of SDO, the less attractive HA careers were perceived to be and the more attractive HE careers were perceived to be. In addition, use of canonical correlation analysis disclosed that perceived career attractiveness cast a unidimensional and bipolar shadow within social dominance attitude space. One end of the bipolar career attractiveness continuum contained only HE careers, whereas the other end of this continuum contained only HA careers (see also Pratto et al., 1994; Pratto, Stallworth, Sidanius, \& Siers, 1997; Sidanius, Pratto, Martin, \& Stallworth, 1991).

There are at least four possible and nonmutually exclusive processes that are generally thought to produce this correspondence between the demands of social roles and the sociopolitical attitudes of personnel within these roles: (a) self-selection, (b) institutional selection, (c) institutional socialization, and (d) differential attrition.

Self-selection implies that persons with relatively high levels of group-based antiegalitarianism (e.g., SDO, racism) will be more attracted to HE jobs, whereas persons with low group dominance values will be more attracted to HA jobs. For example, in two large samples, students with high levels of SDO found HE jobs (e.g., FBI agent, criminal prosecutor) more attractive than HA jobs (e.g., human rights advocate, social worker). Students with low SDO levels showed the opposite pattern (Sidanius, Pratto, Sinclair, et al., 1996).

Institutional selection can be said to occur when people with higher perceived levels of group-based, antiegalitarianism are more likely to be selected for HE jobs, whereas people with higher perceived levels of group-based egalitarian values are more likely to be selected for HA jobs. Some support for this mechanism has recently been found by Pratto et al. (1997). They asked samples of students and business people to make hiring decisions when given information concerning (a) the applicant's gender, (b) the decision maker's gender, (c) the HE versus HA job experience, and (d) whether the job was classified as being HE or HA. Because women have been consistently found to have lower levels of SDO than do men (see Pratto, Sidanius, \& Stallworth, 1993; Pratto et al., 1994; Sidanius \& Liu, 1992; Sidanius \& Pratto, 1993; Sidanius, Pratto, \& Bobo, 1994; Sidanius, Pratto, \& Brief, 1995; Sidanius, Pratto, \& Rabinowitz, 1994), it was expected that women would be deemed more suitable for HA roles and men would be deemed more suitable for HE roles. The results supported this hypothesis and also showed that this gender stereotyping was exhibited to the same degree by both male and female judges.

Institutional socialization can be said to occur when persons in HE roles develop higher levels of group-based antiegalitarianism and persons in HA roles develop higher levels of group-based proegalitarianism as a function of the formal and informal experiences encountered on the job. There are at least two empirical studies that speak to the power of socialization within HE jobs. Carlson and Sutton (1974) found that police recruits became more authoritarian as they progressed through the police academy, and Teahan (1975) found that White police officers became more anti-Black as they proceeded through the police academy (for other socialization effects of police work, see Butler \& Cochrane, 1977; Carlson \& Sutton, 1975; Hazer \& Alvares, 1981; Lefkowitz, 1977; McGahan, 1984; Sutton \& Carlson, 1977; Teahan, Adams, \& Podany, 1980; Van-Maanen, 1975). Similarly, there are two empirical studies that are consistent with the notion that brutal and racist behavior on the part of incumbents of HE roles will actually be rewarded. For example, the Christopher Commission (Christopher et al., 1991) report on the Los Angeles Police Department examined the personnel files of the 44 Los Angeles Police Department officers with an unusually large number of civilian complaints of excessive force, brutality, or improper tactics. In general, the commission found that the supervisor performance evaluations of these 44 officers were very positive and uniformly optimistic about the officer's progress and prospects on the force. Similarly, Leitner and Sedlacek (1976) studied the factors associated with performance evaluations of 52 campus police officers. After controlling for a range of other factors, they found that the greater the racial prejudice of the officers, the more positive their performance evaluations tended to be.

Finally, there is some reason to suspect that differential attrition may also be partly responsible for the correspondence between the HE/HA ideologies of individuals and the HE/HA tendencies of the social roles they find themselves performing. Attrition is here defined as either voluntary or involuntary exiting from an organization. Application of the basic notions of personality/ job congruence from vocational theory (e.g., Gottfredson \& Holland, 1990) to the domain of intergroup relations and institutional discrimination suggests that those in HE roles who have relatively high levels of antiegalitarianism and group dominance values will have greater job satisfaction, receive more positive feedback, and be more successful-and thus will be less likely to leave the organization-than those with relatively egali- 
tarian values. Conversely, among those in HA roles, persons with relatively high group-based egalitarian values will be more successful and thus less likely to exit than those with antiegalitarian values, everything else being equal.

In this study, we will further explore the issue of congruence between antiegalitarian beliefs and $\mathrm{HE} / \mathrm{HA}$-social roles within the university environment. Specifically, we will explore the consequences of the congruence between the HE social ideology of classical racism and majoring in either an $\mathrm{HE}$ or HA subject domain. Given both vocational choice and SD theory, three results should follow:

1. Students with HE college majors should show relatively high levels of group-based antiegalitarianism (i.e., classical racism), whereas students with HA majors should show relatively low levels of classical racism.

2. Everything else being equal, students whose racial beliefs are consistent with the HE/HA nature of their majors (i.e., congruents) should enjoy greater academic rewards (i.e., higher grade point averages [GPAs]) than students whose racial beliefs are not consistent with the $\mathrm{HE} / \mathrm{HA}$ nature of their majors (i.e., incongruents). This implies that there should be a significant interaction between one's level of racism and the HE/HA distinction in college major, with individuals high in antiegalitarianism performing better in HE majors than in HA majors and vice-versa for individuals low in antiegalitarianism.

3. Due to some combination of self-selection, institutional socialization, and differential attrition processes, the probability of congruence between students' racism and college major should increase as a function of educational experience or tenure within the university environment. Thus, we should find some evidence of lower mismatch between racial prejudice and university major among experienced as compared to inexperienced students.

\section{METHOD}

\section{Respondents}

The respondents in this study came from a random sample of 5,655 students from the University of Texas in 1986 in a study of teacher evaluation (Sidanius, 1989). Confidential questionnaires were distributed at the end of the spring semester together with the university's normal instructor evaluation forms and were filled out in the classroom. The majority of the analyses use a subsample of students (83\% undergraduate, $17 \%$ graduate students) who could be classified as having either $\mathrm{HE}$ or HA majors $(N=955)$. Of this sample, 582 were women and 372 were men, with one student not indicating gender. The ethnic breakdown of this sample was as follows: White American $(n=687)$, Mexican American $(n=110)$, African American $(n=20)$, Asian American $(n=$
29), Native American $(n=4)$, foreign students $(n=69)$, and "other" $(n=36)$.

\section{Variables}

HE/HA majors. As discussed earlier, HE social agents (e.g., ideologies, social institutions, social roles) are identified as those social agents that tend to disproportionately benefit those groups at the very top of the social structure (e.g., the wealthy, dominant ethnic groups). Within American and Western society, these dominant groups tend to be based on race, ethnicity, gender, and social class. HA social agents are defined as those agents (ideologies, social institutions, social roles) that tend to disproportionately benefit or work on behalf of subordinate groups or those at the very bottom of the groupbased social hierarchy (e.g., the poor, ethnic and racial minorities).

Given the manner in which SD theory defines HE and HA orientations, only those students whose majors could be clearly and fairly unambiguously classified into either HE or HA categories were closely examined. HA majors were defined as those that were associated with the study of or with beneficial activities directed toward low-status and subordinate social groups. These groups could include low-status racial or ethnic groups, the poor, and the chronically disabled. Therefore, any major that implied help toward and sympathy with the "socially weak" (e.g., ethnic minorities, the poor, the disabled) would be considered an HA major, and any major that implied help toward or sympathy with the "socially powerful" (e.g., the wealthy, business executives) was considered an HE major. Examples of college majors falling into the HA category are fields such as (a) special education, (b) social work, and (c) African and Mexican studies. HE majors, on the other hand, were identified as any major that is associated with strong identification with or activities directed toward powerful and dominant social groups. These powerful groups can be ethnic groups or socioeconomic groups. Given the distribution of majors available, these majors were generally associated with dominant socioeconomic groups such as large corporations, powerful financial interests, and business groups in general (e.g., majors in business administration, finance, marketing).

To assure ourselves that these majors were classified in a reliable fashion, 11 independent judges familiar with the theoretical distinction between $\mathrm{HE}$ and HA norms were given the list of majors and asked to classify them. Using the intraclass correlation coefficient as the index of interjudge reliability, these analyses showed a very high degree of agreement as to how these university majors were to be classified (i.e., $r_{\text {intraclass }}=.96$ ).

The complete list of the HE or HA majors is found in Table 1. Altogether, 457 students were classified as hav- 
TABLE 1: List of Hierarchy-Attenuating (HA) and Hierarchy-Enhancing (HE) College Majors

HA majors
American studies
Anthropology
Asian studies
Ethnic studies: African and Afro-American
Ethnic studies: Mexican American
Latin American studies
Oriental and African languages
Sociology
Special education
Nursing
Social work
HE majors
Accounting
Advertising
Economics
Finance
General business
Management
Marketing administration

ing HA majors, and 498 students were classified as having HE majors. All of those students who had college majors that could be not clearly classified as either HAs or HEs were then labeled intermediates $(n=4,475)$. Intermediates consisted of students with the following majors: architecture and planning, classics, English, French and Italian, geography, Germanic languages, government, history, linguistics, philosophy, psychology, Slavic languages, Spanish and Portuguese, astronomy, botany, chemistry, computer sciences, geological sciences, home economics, marine studies, mathematics, microbiology, physics, zoology, journalism, radio-television-film, speech communication, curriculum and instruction, educational administration, educational psychology, physical and health education, aerospace engineering, chemical engineering, civil engineering, electrical engineering, mechanical engineering, petroleum engineering, biomedical engineering, art, drama, music, law, and library and information science.

GPA was operationalized by asking the students to place their cumulative GPAs into one of five categories: (a) less than $2.00(n=175)$, (b) 2.49 to $2.00(n=975)$, (c) 2.99 to 2.50 ( $n=1,650)$, (d) 3.49 to $3.00(n=1,527)$, and (e) 4.00 to $3.50(n=1,328)$. This five-category GPA scale was then treated as the dependent variable.

Racism was operationalized by an 11-item racism scale (see Table 2). The items comprising this scale were largely inspired by earlier empirical investigations of the racism construct (see, e.g., Brigham, Woodmansee, \& Cook, 1976; Woodmansee \& Cook, 1967). This scale showed a high level of reliability (Cronbach's $\alpha=.90$ ) and face validity. Despite the fact that the scale was
TABLE 2: Items Used in the Racism Scale

\begin{tabular}{|c|c|c|c|}
\hline Item & $M$ & SD & $\begin{array}{c}\text { Correlation } \\
\text { With } \\
\text { Total Scale }\end{array}$ \\
\hline 1. Racial equality & 1.56 & 0.76 & .60 \\
\hline 2. A Black president of the United States & 2.34 & 0.97 & .71 \\
\hline 3. Black neighbors in your neighborhood & 2.16 & 0.93 & .66 \\
\hline 4. Foreigners & 2.47 & 0.98 & .53 \\
\hline 5. Interracial dating should be avoided ${ }^{\mathrm{a}}$ & 2.57 & 1.25 & .63 \\
\hline $\begin{array}{l}\text { 6. Each ethnic group should stay in its } \\
\text { own place }\end{array}$ & 1.82 & 0.89 & .66 \\
\hline $\begin{array}{l}\text { 7. There are too many Blacks on this } \\
\text { campus }^{\text {a }}\end{array}$ & 1.74 & 0.87 & .61 \\
\hline 8. Increased equality & 1.80 & 0.89 & .58 \\
\hline 9. White superiority ${ }^{\text {a }}$ & 1.80 & 0.99 & .64 \\
\hline 10. A Black supervisor & 2.16 & 0.87 & .60 \\
\hline 11. Interracial marriage & 2.79 & 1.20 & .63 \\
\hline Total Racism Scale & 2.11 & 0.78 & - \\
\hline
\end{tabular}

NOTE: Respondents were asked to rate their feelings toward these objects, statements, and events on a scale from 1 (very positive) to 5 (very negative) .

a. These items were reverse coded.

positively skewed, the scale's construct validity was confirmed by its statistically significant relationships with four validity criteria: (a) political conservatism ${ }^{2}(\eta=.42$, $p \leq .0001)$; (b) opposition to busing $(\eta=.30, p \leq .0001)$; (c) opposition to affirmative action $(\eta=.24, p \leq .0001)$; and (d) ethnicity-showing, for example, that European Americans have significantly higher scores than do African Americans $(\eta=.20, p \leq .0001)$.

\section{RESULTS}

\section{Racism by Major}

Our first hypothesis concerns the basic assumption that those classified as having HE majors will have relatively high racism levels, whereas those classified as having HA majors will have relatively low racism scores. This hypothesis was explored by use of two a priori contrasts of the racism levels of those in the HE and HA categories versus intermediates. If our basic assumption of the $\mathrm{HE} / \mathrm{HA}$ distinctions is valid, the HEs should be significantly more racist than intermediates, whereas HAs should be significantly less racist than intermediates. The results of these analyses confirmed both expectations. HEs $(M=2.23, S D=0.68)$ were found to be significantly more racist than were intermediates $(M=$ 2.06, $S D=0.68), t(5391)=5.42, p \leq .0001$, whereas HAs $(M=1.98, S D=0.65)$ were found to be significantly less racist than intermediates, $t(5391)=-2.26, p \leq .02$. These results are not only consistent with theoretical expectations but also provide additional empirical validation for the HE/HA distinction. 


\section{GPA as a Function of Racism and HE/HA Status}

Our second hypothesis concerned whether one's GPA is an interactive function of racism and the $\mathrm{HE} / \mathrm{HA}$ distinction on college major. To begin, consistent with a great deal of previous literature (see Sidanius, 1988; Sussman \& Thompson, 1971; Tabachnick, 1962), we found that students' GPAs tend to be negatively correlated with their levels of racism $(\eta=-.13, p<.0001)$. As expected, there was no real relationship between the $\mathrm{HE} / \mathrm{HA}$ distinction and one's GPA $(M=2.98, S D=0.46$ for HAs vs. $M=3.01, S D=0.54$ for HEs $), F(1,953)=1.75$, $p>.10$. Over and above the main effects of both racism and $\mathrm{HE} / \mathrm{HA}$ major, our primary interest here is the interaction between levels of racism and one's $\mathrm{HE} / \mathrm{HA}$ placement. In our first examination of this issue, we performed a two-stage, hierarchical regression analysis in which the main effects of both the $\mathrm{HE} / \mathrm{HA}$ distinction and racism were entered into the equation. Next, we entered the $\mathrm{HE} / \mathrm{HA} \times$ Racism product term. The addition of this product term was associated with a statistically significant increase in the amount of variance in GPA that could be accounted for by the model, $F(1,915)=$ $10.32, p<.001$. That the nature of this interaction was consistent with expectations was confirmed by inspection of the slopes of GPA regressed on racism among $\mathrm{HE}$ and HA students. The relationship between racism and GPA was significantly more negative for students in HA majors $(b=-.23)$ than for students in HE majors $(b=$ -.08). These results show that students in HA majors had significantly greater GPAs as they were lower in racism than students in HE majors.

Although the effect size of this interaction effect might not seem overly impressive $(r=.102),{ }^{3}$ recent work has convincingly shown that very small effect sizes, in terms of percentage of variance accounted for, can have very substantial consequences in the real world (see e.g., Abelson, 1985; Eagly, 1996; Martell, Lane, \& Emrich, 1996). To demonstrate the nontrivial nature of this effect size in meaningful and easily understandable terms, we constructed a congruency/incongruency distinction by cross-classifying the students according to whether they had high or low racism levels (determined by a median split) and whether they had either HE or HA majors. Thus, congruents were defined as students having HE majors with relatively high racism scores or HA majors with relatively low racism scores. Incongruents, on the other hand, were students with HE majors with relatively low racism scores or HA majors with relatively high racism scores. This procedure generated a total of 534 incongruents and 385 congruents. We then crossclassified the congruent/incongruent distinction by the students' GPAs. As we can see in Table 3, whether there was good match between the students' level of racism and their $\mathrm{HE} / \mathrm{HA}$ major made a meaningful and sub-
TABLE 3: Proportions of Incongruents and Congruents by Level of Academic Success (GPA)

\begin{tabular}{lccc}
\hline Academic Success (GPA) & $\begin{array}{c}\text { Incongruents } \\
(\%)\end{array}$ & $\begin{array}{c}\text { Congruents } \\
(\%)\end{array}$ & $\begin{array}{c}\text { Total } \\
(\%)\end{array}$ \\
\hline Less than 2.00 & 73.7 & 26.3 & 100 \\
$2.00-2.49$ & 55.1 & 44.9 & 100 \\
$2.50-2.99$ & 36.0 & 64.0 & 100 \\
$3.00-3.49$ & 42.4 & 57.6 & 100 \\
$3.50-4.00$ & 37.5 & 62.5 & 100 \\
\hline
\end{tabular}

NOTE: GPA = grade point average.

stantial difference to the likelihood of doing well in school. For example, among those students doing poorly in school (i.e., GPA < 2.00), 73.7\% had a poor match between their levels of racism and their area of study (i.e., incongruents), whereas only $26.3 \%$ of these students had a good match between racism and major (i.e., congruents). However, among those students doing relatively well academically, there was a substantially larger proportion of congruents to incongruents. For example, among the students with a $\mathrm{B}+$ average or better (i.e., a GPA between 3.50 and 4.00 ), only $37.5 \%$ were incongruents, whereas fully $62.5 \%$ were congruents.

\section{Controlling for Possible Confounds}

Our data as well as past research indicate that gender and race tend to be correlated with both $\mathrm{HE} / \mathrm{HA}$ domain and racism (see, e.g., Pratto et al., 1997; Sidanius, Pratto, Sinclair, et al., 1996). For example, females tend to choose HA majors more than do males, $\chi^{2}(1)=49.97$, $p<.001$, and African American and Latino students tend to major in HA majors more than do European and Asian American students, $\chi^{2}(6)=26.41, p<.001$. In addition, there is also consistent work showing that GPA and racism are related to factors such as political conservatism (see, e.g., Sidanius, 1988; Sidanius et al., 1991), gender (Ekehammar, 1985), ethnicity (Sidanius et al., 1991; Steinberg, 1996), and academic rank (Sidanius et al., 1991). To take account of these possible confounds, we repeated the two-stage hierarchical regression by including not only the main effects of racism and the $\mathrm{HE} / \mathrm{HA}$ distinction but also the covariates of (a) gender; (b) political conservatism; (c) the students' academic rank (e.g., 1 st year, 2nd year, etc.); and (d) ethnicity (dummy-variable coded). ${ }^{4}$ Because the data contained seven ethnic categories (see categories above), only six dummy ethnicity vectors were needed to account for the ethnicity factor. The ethnic category "other" was used as the ghost or contrast category.

Despite the controls, the results of this second regression analysis were very much like the first. The addition of the product term indicated the presence of a statistically significant interaction between racism and the 
$\mathrm{HE} / \mathrm{HA}$ distinction, $F(1,882)=4.14, p \leq .05$. Although slightly less dramatic than before, the pattern of these residual GPA scores were very much the same as without the controls in that the relationship of racism with GPA is significantly more negative among students in HA majors $(b=-.17)$ than among students in HE majors $(b=-.09)$. These results indicate that the interaction is not simply a function of the effects of either gender, ethnicity, political ideology, or student rank.

\section{USING A STRICTER DEFINITION OF HE AND HA MAJORS}

To check that our results were not simply a function of some arbitrary decision on our part to categorize some majors as HE majors and others as HA majors, we identified a subset of the best and purest examples of HE and HA majors and recomputed the regression analyses using this new categorization. Specifically, for the HE category, we only included those majoring in economics, accounting, finance, general business, marketing, management, and advertising. For the HA category, we only included majors in sociology, special education, and social work.

Despite the drop in sample size that resulted from this recategorization, the effects mirrored those of the original categorization (and were even a little stronger). The analysis without controls revealed a significant interaction between levels of racism and the HE/HA-major distinction, $F(1,753)=13.67, p<.0002$. As before, the slope of the relationship between racism and GPA was significantly more negative for students in HA majors $(b=-.26)$ than for students in HE majors $(b=-.06)$.

Once again, we further assured ourselves that these effects were not trivial by performing the same type of cross-classification of GPA by congruency that is found in Table 3, and once again, the results also showed the same pattern as found in Table 3. For example, among those students with poor grades (i.e., GPA<2.00), 70.6\% were incongruents, whereas only $29.4 \%$ were congruents. In contrast, among those students who were very academically successful (i.e., GPA 3.50 to 4.00 ), only $39.3 \%$ were incongruents, whereas fully $60.7 \%$ were congruents.

Finally, these results held even after including controls for gender, ethnicity, political conservatism, and students' academic rank (e.g., 1st year, 2nd year, etc.), again revealing an interaction between racism and the $\mathrm{HE} / \mathrm{HA}$-major distinction, $F(1,724)=8.07, p<.005$. Again, the simple slope of racism on GPA was significantly more negative for students in HA majors $(b=-.21)$ than for students in HE majors $(b=-.07)$. As a whole, these results show that the interaction between levels of racism and the HE/HA-major distinction in predicting GPA are not simply a function of an arbitrary distinction made by us between students' majors.

\section{EXPOSURE TO THE UNIVERSITY ENVRONMENT}

According to vocational interest theory (e.g., Holland, 1985), we have reason to suspect that in a given sector, profession, or academic major, the degree of match between people's personalities and general social attitudes and the social roles they are to play should increase over time. This may occur for a variety of reasons, such as socialization into the social role or differential attrition of incongruents from the social role. Thus, whatever the precise process, we should expect that the longer people are associated with either HE or HA social environments, the greater the degree of match or congruence between their levels of racism and their HE or HA social environments.

If this increasing congruence hypothesis is correct, we should expect the percentage of congruents to be significantly higher among upper-division students (i.e., juniors and seniors) than among lower-division students (i.e., 1st-year students and sophomores). To examine this hypothesis, we cross-classified the students by congruency (congruents vs. incongruent) and university experience (lower division vs. upper division). In this case, we used an even stricter definition of congruence and defined congruents as students in HE majors with relatively high racism scores (i.e., highest one third of the racism distribution) and HA majors with relatively low racism scores (i.e., lowest one third of the racism distribution). ${ }^{5}$ Incongruents were defined as HE majors with relatively low racism scores and HA majors with relatively high racism scores. This procedure generated a total of 250 incongruents and 387 congruents.

The first step in the examination of this hypothesis involved a simple cross-classification analysis in which congruence was crossed with educational tenure (1st-year to graduate student). The results of this cross-classification confirmed our expectations. In addition, this tenure effect was also far from trivial. For example, among 1 st-year students, there was a larger proportion of incongruent to congruent students $(57.6 \%$ vs. $42.4 \%$, respectively), whereas among graduate students, there was substantially smaller proportion of incongruent to congruent students ( $35 \%$ vs. $65 \%$ ). These distributional differences were found to be statistically significant, $\chi^{2}(4)=17.44, p<.002, \phi=.17$. Figure 1 shows this pattern in terms of standardized residuals for each congruencyby-seniority combination. ${ }^{6}$ Residuals greater than zero indicate that there are more individuals in the cell than may be expected, given the null hypothesis. Likewise, residuals less than zero indicate that there are fewer individuals in that cell then there should be, given the null hypothesis. As Figure 1 indicates, in the 1 st year, incongruents are greatly overrepresented (standardized residual $=2.7$ ), whereas congruents are greatly underrepresented (standardized residual $=-2.2$ ). Among 


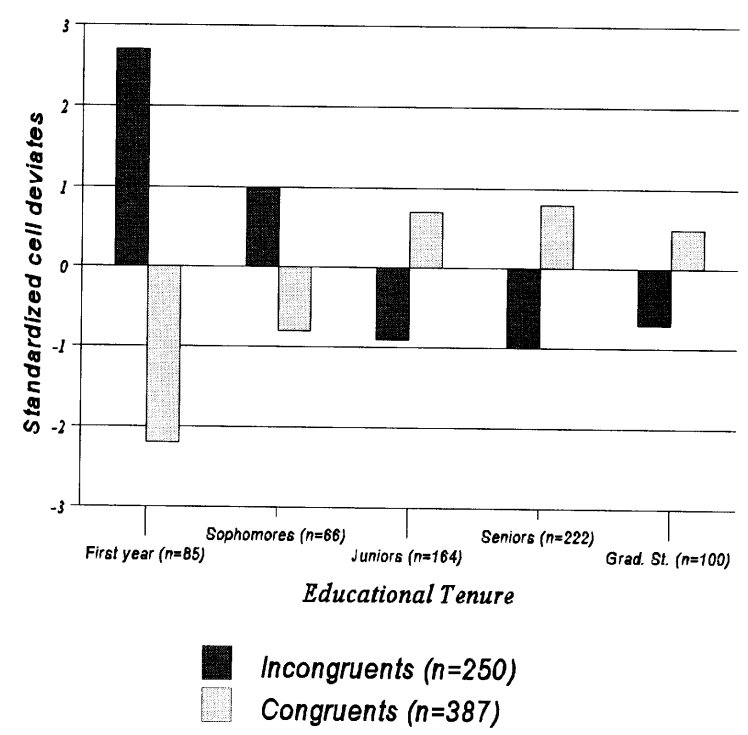

Figure 1 Cross-classification of congruency by educational seniority.

graduate students, the situation is reversed: Congruents are overrepresented (standardized residual $=0.5$ ), and incongruents are underrepresented (standardized residual $=-0.7$ ). As a whole, Figure 1 shows that the probability that students' racial attitudes will be congruent with their major areas of study increases over time.

To see whether this tendency toward greater congruency held even after controlling for a number of other possibly confounding factors, we computed a stepwise, logistic regression analysis. In this analysis, we examined the probability of being either a congruent or an incongruent as a function of a series of independent variables. In order of entry into the logistic regression analysis, these variables were (a) gender, (b) ethnicity, (c) political conservatism, (d) the main effect of racism and the main effect of the HE/HA distinction, (e) GPA, and (f) educational seniority. The purpose of entering educational seniority into the equation last was to see if tenure within the university increased the probability of being congruent after the effects of the previous variables had all been considered (see Table 4).

The results of this hierarchical logistic regression analysis indicated that there were a number of factors associated with the probability of being a congruent. These variables included gender (i.e., being male; $R=$ $-.05)$, ethnicity $(R=.11)$, and consistent with the results presented earlier, GPA $(R=.10) .^{7}$ More to the point, however, the analysis also showed that even after control-
TABLE 4: Logistic Regression Analysis of Congruence Between Racism and College Major as a Function of Gender, Ethnicity, Political Conservatism, Racism, the HE/HA contrast, GPA, and Educational Tenure

\begin{tabular}{|c|c|c|c|c|}
\hline Step & Independent Variable & $\begin{array}{c}\text { Incremental } \\
\chi^{2} \text { for } \\
\text { Improvement } \\
\text { in Model Fit }\end{array}$ & $\begin{array}{l}\text { Wald } \\
\text { Statistic }\end{array}$ & $\begin{array}{c}R \\
\text { Statistic }\end{array}$ \\
\hline 1. & Gender & $3.96 *$ & 3.92 & -.05 \\
\hline 2. & Ethnicity & $24.98 * * *$ & 21.73 & .11 \\
\hline 3. & Political conservatism & 0.14 & - & - \\
\hline 4. & $\begin{array}{l}\text { Main effect of racism and main } \\
\text { effect of HE/HA distinction }\end{array}$ & 0.99 & - & - \\
\hline 5 . & GPA & $11.07 * * *$ & 10.84 & .10 \\
\hline 6. & Educational tenure & $6.37 * *$ & 6.34 & $.07 *$ \\
\hline
\end{tabular}

NOTE: $\mathrm{HE}=$ hierarchy enhancing; $\mathrm{HA}=$ hierarchy attenuating; $\mathrm{GPA}=$ grade point average.

$* p \leq .05 . * * p \leq .01 . * * * p \leq .001$.

ling for all previous variables, increasing experience within the university environment (i.e., student tenure) was still associated with a higher probability of congruence between one's level of racism and one's area of academic specialization $(R=.07, p \leq .01)$.

\section{DISCUSSION}

According to SD theory, because HE organizations will tend to differentially allocate resources to members of high- and low-status groups (e.g., races, ethnicities, social classes), we should therefore expect these institutions to be disproportionally staffed by personnel with relatively high discriminatory attitudes and predispositions. Likewise, because HA organizations will tend to produce greater levels of equality between social groups, one should also expect these organizations to be disproportionately staffed by persons with relatively egalitarian values. Holland's (1985) vocational choice theory suggests that those whose personalities are congruent with the general occupational environment will be more satisfied with their jobs and are also more likely to be rewarded and successful in those jobs. In conjunction, these theories predict that students whose level of antiegalitarianism (racism) is congruent with the HE/HA nature of their academic major should be more successful and satisfied than those students whose level of antiegalitarianism is incongruent with the $\mathrm{HE} / \mathrm{HA}$ nature of their academic major.

Based on both occupational choice and SD theory, we tested three hypotheses. First, we expected that if we regard classical racism as one special case of group-based antiegalitarianism, then we should find that those with HE majors should have relatively high levels of racism, whereas those with HA majors should have relatively low levels of racism. Second, because group-based antiegali- 
tarianism is an important and dynamic factor separating $\mathrm{HE}$ and HA social roles, we also expected that institutional reward should be an interactive function of one's level of racism and the HE versus HA distinction of one's college major. This implies that those students whose racial ideology is congruent with their domain of study (HE vs. HA) should receive greater institutional rewards in the form of higher GPAs than those whose racism is incongruent with their HE or HA domain of study. Third and finally, due to the effects of self-selection, social role socialization, and/or differential attrition, we expected that students who have attended the university longer should show a higher degree of congruence between their racial ideologies and the HE/HA nature of their college majors. Thus, the probability that those with relatively low racism scores should be found within HA majors, and those with relatively high racism scores within HE majors should increase with longer institutional tenure. The empirical results confirmed all three hypotheses.

Consistent with our first hypothesis, the fact that students within HA majors had relatively low racism scores whereas those with HE majors had relatively high racism scores is consistent with a growing body of work generated by SD theory. SD theorists have recently shown that those either functioning in or attracted to HE social roles (e.g., a police officer or business person) possess relatively high levels of SDO and racism, whereas those functioning in or attracted to HA social roles (social worker, human rights advocate) have relatively low levels of social dominance orientation and racism, independent of demographic differences such as social class, gender, age, education, or ethnicity (Pratto et al., 1994; Sidanius, Pratto, Sinclair, \& van Laar, 1996). These results are also consistent with earlier findings produced by researchers outside of the SD paradigm showing that police officers have relatively high levels of racism (see, e.g., Colman \& Gordan, 1982; Fyfe, 1982; Wortley \& Homel, 1995; cf. Cochran, 1974; Hollinger, 1984; Huang \& Singer, 1984).

Consistent with our second hypothesis, not only did the data presented in this article indicate significant differences in racism levels between HE and HA majors, but they also provided evidence for an interaction between level of racism and the HE/HA distinction, such that students in majors that are congruent with their racial attitudes tend to receive better grades than students in majors that are incongruent with their racial attitudes. Moreover, we found that even though the interaction between racism and the $\mathrm{HE} / \mathrm{HA}$ distinction accounted for a relatively small amount of variance in GPA consistent with other recent explorations of the effect size issue (Abelson, 1985; Eagly, 1996; Martell et al., 1996), when the data are framed in a manner that is easily comprehended and in everyday terms, this interaction between racism and $\mathrm{HE} / \mathrm{HA}$ categorization was found to be far from trivial. In particular, additional analyses showed that a substantially higher proportion of those receiving poor grades were likely to be incongruents rather than congruents. Furthermore, use of multiple regression analysis showed that this interaction between racism and the $\mathrm{HE} / \mathrm{HA}$ distinction remained significant even after controlling for a number of other possible confounding variables such as gender, ethnicity, political conservatism, student rank, and of course, the main effects of both racism and the $\mathrm{HE} / \mathrm{HA}$ distinction.

In addressing our third hypothesis, we showed that the degree of ideological/social role congruence was higher among students with longer tenure at the university. Use of hierarchical logistic regression analysis revealed that this trend held even after controlling for a number of possible confounds such as gender, ethnicity, political conservatism, GPA, and the main effects of racism and the $\mathrm{HE} / \mathrm{HA}$ distinction. Once again, although there has been some evidence consistent with this general thesis among police officers in the field (Carlson \& Sutton, 1974), as far as we know, this thesis has never been empirically tested before within populations as young as university students and never with respect to the congruence between racism and the general $\mathrm{HE} / \mathrm{HA}$ distinction.

In reviewing our findings, it is also important that we be clear about what we are not saying. Namely, we are not implying that racists get higher grades than nonracists in HE majors. Rather, we are saying that net of the main effects of racism, the $\mathrm{HE} / \mathrm{HA}$ distinction, and several other factors, those whose racial attitudes are congruent with their college majors tend to receive higher grades than those whose racial attitudes are incongruent with their college majors. We are also not saying that students in HE majors necessarily become more racist over time. Instead, consistent with much other research, our findings disclose that GPA tended to be negatively correlated with racism scores for all students in all majors and that racism scores tended to decrease with increasing educational sophistication (Kutner, 1951; Kutner \& Gordan, 1964; Sidanius, 1988; Sidanius et al., 1991; Sussman \& Thompson, 1971; Tabachnick, 1962; see also Nilsson, Ekehammar, \& Sidanius, 1987). However, we did find that net of all other factors we could examine, students with greater exposure to the university environment were more likely to have racial attitudes that were congruent with the $\mathrm{HE} / \mathrm{HA}$ nature of their educational majors. Finally, although the interaction between the HE/HA distinction and racism is clearly associated with academic success, even net of obvious demographic factors the correlational nature of these data clearly do not allow us to 
conclude that the specific interaction between the $\mathrm{HE} / \mathrm{HA}$ distinction and racism is the causative agent affecting one's level of academic success. Coming to such a causative conclusion would entail the ability to directly and experimentally manipulate the level of racism, antiegalitarianism, or SDO, which is a situation that would be very difficult-if not impossible-to achieve.

Therefore, although we must remain cautious as to what the causal structure of these relationships is, this type of interaction between the HE/HA nature of one's racial ideology and the HE/HA nature of one's area of specialization is clearly consistent with and derivable from SD theory and vocational choice theory. Furthermore, to our knowledge, this is the first time this specific question has been empirically explored. It is also interesting to note that whereas vocational choice theorists do not recognize or distinguish between HE or HA social roles, if one accepts this SD theory distinction as valid, then the results found here would be perfectly consistent with the overall nature of vocational choice theory. This is to say, if incumbents of HE social roles tend to discriminate against members of subordinate groups, and those in HA social roles tend to resist discrimination against subordinate groups, then we should not only expect incumbents of $\mathrm{HE}$ and HA roles to have significantly different levels of antiegalitarian ideologies, but we should also expect that those incumbents whose egalitarian ideologies are congruent with the social roles they are to perform will be more successful in these roles than those whose egalitarian ideologies are not congruent with these roles. Therefore, these data are consistent with and extend earlier findings concerning the interface between career choice and ideology (see Holland, 1966; Pratto et al., 1994, 1997; Sidanius et al. 1991; Sidanius, Pratto, Sinclair, et al., 1996).

Relatively high antiegalitarianism in HE organizations as compared to HA organizations is likely to have profound effects on levels of group discrimination. Support for this can be found in the results of recent field experiments on discrimination. Use of situation and correspondence testing with equally qualified and matched job applicants has disclosed a consistent and rather substantial level of racial and ethnic discrimination in countries such as the United States, the Federal Republic of Germany, Great Britain, the Netherlands, Spain, and Canada. The results of these field experiments show that, everything else being equal, White and majority group job applicants receive as many as 4 times the number of job offers as equally qualified Blacks, Hispanics, and applicants from other ethnic minorities (Bovenkerk, Gras, \& Ramsoedh, 1994; Fix \& Bean, 1990; Fix \& Struyk, 1993; Goldberg, Mourinho, \& Kulke, 1996; Turner, Fix, \& Struyk, 1991; see also Zegers de Beijl, 1996). Most pertinently, however, the data show that the rate of job discrimination is between 2 and 6 times greater within the private sector than within the public sector (Bovenkerk et al., 1994; Goldberg et al., 1996). Because HE roles tend to be found in the private sector and HA roles tend to be located in the public sector, our findings suggest that these differences in discrimination rates between the public and private sector may be due in part to the HE/HA orientation of the incumbents of these roles.

Although the fact that the increasing congruence between racial attitudes and university major as a function of increasing exposure to the university environment seems quite clear and consistent with the reasoning of both vocational choice and SD theories, the exact psychosocial processes producing these results are far from clear. As mentioned in the introduction, there are at least four nonmutually exclusive processes that might help drive this phenomenon: self-selection, institutional selection, institutional socialization, and differential attrition processes. As also mentioned before, previous empirical research has found relatively unambiguous support for at least three of these possible four mechanisms. However, thus far, there has been no direct or indirect evidence showing that increased congruence between group-based antiegalitarianism (e.g., racism, $\mathrm{SDO}$ ) and HE/HA roles is a function of differential attrition effects. The evidence before us here is certainly consistent with a differential attrition hypothesis. Specifically, we find that there are fewer incongruents present later in college than earlier in college. However, because the study before us used a cross-sectional rather than a longitudinal design, we are not able to conclude decisively if any attrition mechanisms are operative. Indeed, it is possible that increased congruence later in college is a function of institutional socialization or self-selection rather than attrition. As there is little, if any, institutional selection operative in the choice of students' major subject, such an explanation probably could not account for the results we find here. However, such institutional selection is very likely to play a role in the establishment of congruency in domains other than students' majors, such as career choice. As matters stand now, we have no reason to rule out any of these basic processes, and we would not be surprised if all four mechanisms play some role. To get a firmer grip on these processes, we are now in the early stages of a 4year longitudinal study examining changes in intergroup attitudes as a function of continued exposure to the university environment.

Although we have examined correlates of the congruence between racial ideology and $\mathrm{HE} / \mathrm{HA}$ domain choice while controlling for a number of other factors such as gender, ethnicity, and political ideology, some might argue that other possible confounding variables should be considered as well. Among these other vari- 
ables might be factors such as authoritarianism (Adorno, Frenkel-Brunswik, Levinson, \& Sanford, 1950; see also Altemeyer, 1996). Although the authoritarianism hypothesis is certainly plausible, research by Leitner and Sedlacek (1976) suggests that authoritarianism cannot account for the findings before us. Specifically, Leitner and Sedlacek administered a battery of personality and attitudes measures to 52 campus police officers in an effort to explore the factors associated with success in a police career. The officers' success was determined by nine criteria, including tenure, number of commendations and reprimands, least absenteeism, performance ratings by supervisors, paired comparison peer ratings, and self and immediate-supervisor ratings. Among the factors possibly associated with this success, Leitner and Sedlacek included two well-known measures of authoritarianism (i.e., the Rokeach Dogmatism Scale and the California F Scale) as well as the California Psychological Inventory and a measure of racial prejudice. The results of multiple regression analysis showed that, even after controlling for the two authoritarianism measures, racism was still found to make an independent contribution to the success of officers within a police career. Net of the other factors, including authoritarianism, the higher the police officers' racism scores, the more successful they were judged to be.

Although we were unable to statistically control for authoritarianism in our analyses, we were able to control for political conservatism. Despite this control, our results continued to show an independent effect of racism. The independent contributions of racism and SDO to career choice, net of other social attitudes such as political conservatism or social conservatism, have also been documented in a study of public defenders (i.e., HAs) and police officers (i.e., HEs) in Los Angeles County (see Sidanius, Liu, et al., 1994). In that study, Sidanius and his colleagues used multiple discriminant analysis to explore the number and nature of those social attitudes that were best able to discriminate between public defenders (HAs) and police officers (HEs). The attitude dimensions used were (a) political conservatism, (b) punitiveness, (c) caste-maintenance orientation (i.e., opposition to interracial marriage), (d) social conservatism (e.g., support for increased aid to the poor), (e) racism, and (f) SDO. The results showed that even after controlling for all of the standard demographic factors (i.e., age, gender, ethnicity, education, social class) and the other discriminating social attitudes such as political and social conservatism, the social attitudes making the strongest independent contributions to the differentiation between HAs (i.e., public defenders) and HEs (i.e., police officers) were the dimensions of racism and SDO. Taken together, these findings suggest that the dimensions of racism and SDO indeed make important and independent contributions to both career choice and career success in HA and HE domains over and above the effects of other potentially relevant dimensions.

In conclusion, these data are important because (a) they support the growing evidence showing a correspondence between basic antiegalitarian values and domain of career specialization, (b) they provide the first concrete and somewhat nonintuitive evidence showing the association between academic success and the congruence between one's antiegalitarian values (i.e., racism) and HE/HA academic specialization, and (c) they provide the first concrete evidence demonstrating a relationship between the amount of exposure to an institutional environment and increasing congruence between racial ideology and HE/HA domain choice. Furthermore, these results are of theoretical interest in that they are quite consistent with and derivable from the combined assumptions of vocational choice and social dominance theories. Further research is clearly needed to unravel the precise mediational mechanisms producing both higher grades among congruents and the correlation between congruency and institutional incumbency.

\section{NOTES}

1. Social dominance orientation (SDO) is defined as a very generalized support for group-based inequality and dominance. Although related to interpersonal dominance, political conservatism, racism, and authoritarianism, SDO is both conceptually and empirically distinguishable from these constructs (see Pratto, Sidanius, Stallworth, \& Malle, 1994).

2. Political conservatism was measured by a single item asking respondents to classify their political beliefs as either (a) very liberal, (b) liberal, (c) middle of the road, (d) conservative, or (e) very conservative.

3. This $r$ coefficient is simply the square root of the percentage of extra variance accounted for, over and above the main effects of racism and the HE/HA distinction.

4. Unfortunately, this secondary data set did not contain information regarding the students' social class. However, given the specific nature of the sample and the dependent variables under study, we do not feel that this is a major problem. Not only does our experience with this student body indicate that the students are overwhelmingly middle and upper class, but a consistent body of research has also shown that race and not social class is the dominant factor associated with academic success (see Steinberg, 1996).

5 . The following analyses were also conducted with a median split on racism such that high racism scores were defined as those above the median and low racism scores were defined as those below the median. Although the trends were in the expected direction, the findings were marginally significant. In an effort to get a purer measure of this construct, we used the top and bottom third of the racism distribution.

6 . The standardized residual provides a readily interpretable index of the degree to which the observed frequency in a cell deviates from the expected frequency for that cell. The standardized residual is given as

$$
z_{p}=\frac{x-\mu}{\sqrt{\mu}}
$$

in which $x$ is the observed frequency for a cell and $\mu$ is the expected frequency for that cell. For large $N, z_{\mathrm{p}}$ is approximately normally distributed (see Wickens, 1989, pp. 134-137). 
7. Note that in logistic regression analysis, the $R$ coefficient can be interpreted as a multiple partial correlation coefficient indicating that as the independent variable increases in value, so does the likelihood of the event occurring. In this case, the event is defined as being a congruent.

\section{REFERENCES}

Abelson, R. (1985). A variance explanation paradox: When a little is a lot. Psychological Bulletin, 97, 129-133.

Adorno, T. W., Frenkel-Brunswik, E., Levinson, D. J., \& Sanford, R. N. (1950). The authoritarian personality. New York: Harper.

Altemeyer, B. (1996). The authoritarian specter. Cambridge, MA: Harvard University Press.

Bovenkerk, F., Gras, M.J.I., \& Ramsoedh, D. (1994). Discrimination against migrant workers and ethnic minorities in access to employment in the Netherlands. In International Migration Papers, 4, 3-59.

Brigham, J. C., Woodmansee, J. J., \& Cook, S. W. (1976). Dimensions of verbal racial attitudes: Interracial marriage and approaches to racial equality. Journal of Social Issues, 32, 9-21.

Butler, A. J., \& Cochrane, R. (1977). An examination of some elements of the personality of police officers and their implications. Journal of Police Science and Administration, 5, 441-450.

Carlson, H. M., \& Sutton, M. S. (1974). The development of attitudes as a function of police roles. Personality and Social Psychology Bulletin, $1,113-115$.

Carlson, H. M., \& Sutton, M. S. (1975). The effects of different police roles on attitudes and values. Journal of Psychology, 91, 57-64.

Chevigny, P. (1995). Edge of the knife: Police violence in the Americas. New York: New Press.

Christopher, W. A., Argellas, J. A., Barnes, W. R., Estrada, L. F., Kantor, M., Mosk, R. M., Ordin, A. S., Slaughter, J. B., \& Tranquada, R. E. (1991). Report of the Independent Commission on the Los Angeles Police Department. Los Angeles: Independent Commission on the Los Angeles Police Department.

Cochran, N. (1974). Dogmatism and social control: Some personality characteristics of police officers. Personality and Social Psychology Bulletin, 1, 213-215.

Colman, A. M., \& Gordan, L. P. (1982). Conservatism, dogmatism and authoritarianism in British police officers. Sociology, 16, 1-11.

Eagly, A. H. (1996). Differences between women and men: Their magnitude, practical importance, and political meaning. American Psychologist, 51, 158-159.

Ekehammar, B. (1985). Sex differences in socio-political attitudes revisited. Educational Studies, 11, 3-9.

Fix, M., \& Bean, F. (1990). The findings and policy implications of the GOA report and the Urban Institute hiring audit. International Migration Review, 24, 817-827.

Fix, M., \& Struyk, R. (1993). Clear and convincing evidence: Measurement of discrimination in America. Washington, DC: Urban Institute Press.

Fyfe, J. J. (1982). Blind justice: Police shootings in Memphis. Journal of Criminal Law E Criminology, 73, 707-722.

Goldberg, A., Mourinho, D., \& Kulke, U. (1996). Labour market discrimination against foreign workers in Germany. In International Migration Papers, 7, 3-57.

Gottfredson, G. D., \& Holland, J. L. (1990). A longitudinal test of the influence of congruence: Job satisfaction, competency utilization, and counterproductive behavior. Journal of Counseling Psychology, 37, 389-398.

Hazer, J. T., \& Alvares, K. M. (1981). Police work values during organizational entry and assimilation. Journal of Applied Psychology, 66, 12-18.

Helms, S. T., \& Williams, G. D. (1973). An experimental study of the reactions of high school students to simulated jobs (Research Report No. 161) . Baltimore: Center for Organization of Schools, John Hopkins University. (ERIC Document Reproduction Service No. ED 087 882)

Henry, P. (1989). Relationship between academic achievement and measured career interest: Examination of Holland's theory. Psychological Reports, 64, 35-40.

Holland, J. L. (1959). A theory of vocational choice. Journal of Counseling Psychology, 6, 35-44.
Holland, J. L. (1966). The psychology of vocational choice. Waltham, MA: Blasidell.

Holland, J. L. (1985). Making vocational choices: A theory of vocational personalities and work environments. Englewood Cliffs, NJ: Prentice Hall.

Holland, J. L. (1996). Exploring careers with a typology: What we have learned and some new directions. American Psychologist, 51, 397-406.

Hollinger, R. C. (1984). Race, occupational status, and pro-active police arrest for drinking and driving. Journal of Criminal Justice, 12, 173183.

Huang, M. S., \& Singer, A. E. (1984). Ethnic group stereotyping by police and university students in New Zealand. Journal of Psychology, $116,89-93$.

Kutner, B. (1951). Patterns of mental functioning associated with prejudice in children. American Psychologist, 6, 328-329.

Kutner, B., \& Gordan, N. B. (1964). Cognitive functioning associated with prejudice: A nine year follow-up study. Sociometry, 27, 66-74.

Lefkowitz, J. (1977). Industrial-organizational psychology and the police. American Psychologist, 32, 346-364.

Leitner, D. W., \& Sedlacek, W. E. (1976). Characteristics of successful campus police officers. Journal of College Student Personnel, 17, 304308.

Martell, R. F., Lane, D. M., \& Emrich, C. (1996). Male-female differences: A computer simulation. American Psychologist, 51, 157-158.

McGahan, P. (1984). Police imagery of the urban environment. Canadian Police College Journal, 8, 107-153.

Mount, M. K., \& Muchinsky, P. M. (1978) . Person-environment congruence and employee job satisfaction: A test of Holland's theory. Journal of Vocational Behavior, 13, 84-100.

Nafziger, D. H., Holland, J. L., \& Gottfredson, G. D. (1975). Studentscollege congruence as a predictor of satisfaction. Journal of Counseling Psychology, 22, 132-139.

Nilsson, E., Ekehammar, B., \& Sidanius, J. (1987). Education and ideology: Basic aspects of education related to adolescents' sociopolitical attitudes. Political Psychology, 8, 395-411.

Posthuma, A. B., \& Navran, L. (1970). Relation of congruence in student-faculty interests to achievement in college. Journal of Counseling Psychology, 17, 35 2-356.

Pratto, F., Sidanius, J., \& Stallworth, L. M. (1993). Sexual selection and the sexual and ethnic basis of social hierarchy. In L. Ellis (Ed.), Social stratification and socioeconomic inequality: A comparative biosocial analysis (pp. 111-136). New York: Praeger.

Pratto, F., Sidanius, J., Stallworth, L. M., \& Malle, B. F. (1994). Social dominance orientation: A personality variable predicting social and political attitudes. Journal of Personality and Social Psychology, 67, 741-763.

Pratto, F., Stallworth, L., Sidanius, J., \& Siers, B. (1997). The gender gap in occupational role attainment: A social dominance approach. Journal of Personality and Social Psychology, 72, 37-53.

Richards, J. M. Williams, G. D., \& Holland, J. L. (1978). An evaluation of the 1977 Minority Introduction to Engineering Summer Program (Report No. 270). Baltimore: Johns Hopkins University Center for Social Organization of Schools.

Rokeach, M. (1960). The open and closed mind. New York: Basic Books.

Sidanius, J. (1988). Political sophistication and political deviance: A structural equation examination of context theory. Journalof Personality and Social Psychology, 55, 37-51.

Sidanius, J. (1989). Racial discrimination and job evaluation: The case of university faculty. National Journal of Sociology, 3, 223-257.

Sidanius, J. (1993). The psychology of group conflict and the dynamics of oppression: A social dominance perspective. In S. Iyengar \& W. J. McGuire (Eds.), Explorations in political psychology (pp. 183-219). Durham, NC: Duke Press.

Sidanius, J., Levin, S., \& Pratto, F. (1996). Consensual social dominance orientation and its correlates within the hierarchical structure of American society. International Journal of Intercultural Relations, 20, 385-408.

Sidanius, J., \& Liu, J. H. (1992). The Gulf War and the Rodney King beating: Implications of the general conservatism and social dominance perspectives. Journal of Social Psychology, 132, 685-700.

Sidanius, J., Liu, J. H., Pratto, F., \& Shaw, J. (1994). Social dominance orientation, hierarchy-attenuators and hierarchy-enhancers: Social 
dominance theory and the criminal justice system. Journal of A pplied Social Psychology, 24, 338-366.

Sidanius, J., \& Pratto, F. (1993). The inevitability of oppression and the dynamics of social dominance. In P. Sniderman \& P. Tetlock (Eds.), Prejudice, politics, and the American dilemma (pp. 173-211). Stanford, CA: Stanford University Press.

Sidanius, J., Pratto, F., \& Bobo, L. (1994). Social dominance orientation and the political psychology of gender: A case of invariance? Journal of Personality and Social Psychology, 67, 998-1011.

Sidanius, J., Pratto, F., \& Bobo, L. (1996) . Racism, conservatism, affirmative action and intellectual sophistication: A matter of principled conservatism or group dominance? Journal of Personality and Social Psychology, 70, 476-490.

Sidanius, J., Pratto, F., \& Brief, D. (1995). Group dominance and the political psychology of gender: A cross-cultural comparison. Political Psychology, 16, 381-396.

Sidanius, J., Pratto, F., Martin, M., \& Stallworth, L. (1991). Consensual racism and career track: Some implications of social dominance theory. Political Psychology, 12, 691-721.

Sidanius, J., Pratto, F., \& Rabinowitz, J. L. (1994). Gender, ethnic status, and ideological asymmetry: A social dominance interpretation. Journal of Cross Cultural Psychology, 25, 194-216.

Sidanius, J., Pratto, F., Sinclair, S., \& van Laar, C. (1996) . Mother Teresa meets Genghis Khan: The dialectics of hierarchy-enhancing and hierarchy-attenuating career choices. Social Justice Research, 9, 145170.

Steinberg, L. (1996). Beyond the classroom: Why schoolreform has failed and what parents need to do. New York: Simon \& Schuster.

Sussman, E., \& Thompson, G. R. (1971). Prejudice as a function of intellectual level and cultural information. Washington, DC: American Educational Research Association.
Sutton, M. S., \& Carlson, H. M. (1977). Attitude and personality differences among men and women studying police science. Journal of Social Psychology, 102, 161-162.

Tabachnick, B. (1962). Some correlates of prejudice toward Negroes in elementary age children. Joumal of Genetic Psychology, 100, 193203.

Teahan, J. E. (1975). A longitudinal study of attitude shifts among Black and White police officers. Journal of Social Issues, 31, 47-56.

Teahan, J. E., Adams, K. M., \& Podany, E. C. (1980). A comparison of the value structure of British and U.S. police. International Journal of Social Psychiatry, 26, 246-254.

Tranberg, M., Slane, S., \& Ekeberg, S. E. (1993). The relation between interest congruence and satisfaction: A meta analysis. Journal of Vocational Behavior, 42, 253-264.

Turner, M., Fix, M., \& Struyk, R. (1991). Opportunities diminished, opportunities denied. Washing ton, DC: The Urban Institute.

Van Maanen, J. (1975). Police organization: A longitudinal examination of job attitudes in an urban police department. Administrative Science Quarterly, 20, 207-228.

Wickens, T. D. (1989). Multiway contingency tables analysis for the social sciences. Hillsdale, NJ: Lawrence Erlbaum.

Woodmansee, J., \& Cook, S. W. (1967). Dimensions of verbal racial attitudes: Their identification and measurement. Journal of Personality and Social Psychology, 7, 240-250.

Wortley, R. K., \& Homel, R. J. (1995). Police prejudice as a function of training and outgroup contact: A longitudinal investigation. Law E Human Behavior, 19, 305-317.

Zegers de Beijl, R. (1996). Combating discrimination against (im)migrant workers and ethnic minorities in the world of work. Geneva, Switzerland: International Labour Office.

Received July 29, 1997

Revision Accepted March 6, 1998 